\title{
Operando Analyses of Solar Fuels Light Absorbers and Catalysts
}

Hans-Joachim Lewerenz $^{1,2^{*}}$, Michael F. Lichterman ${ }^{1,3^{*}}$, Matthias H. Richter ${ }^{1,3^{*}}$, Ethan J. Crumlin $^{4}$, Shu $\mathrm{Hu}^{1,3}$, Stephanus Axnanda ${ }^{4}$, Marco Favaro ${ }^{4,5,6}$, Walter Drisdell ${ }^{5,6}$, Zahid Hussain ${ }^{4}$, Bruce S. Brunschwig ${ }^{1,7}$, Zhi Liu ${ }^{4,8,9}$, Anders Nilsson ${ }^{10}$, Alexis T. Bell ${ }^{6,11}$, Nathan S. Lewis ${ }^{1,3,7}$, Daniel Friebel ${ }^{10}$

${ }^{1}$ Joint Center for Artificial Photosynthesis, California Institute of Technology, Pasadena, CA 91125, USA.

${ }^{2}$ Division of Engineering and Applied Science, California Institute of Technology, Pasadena, CA 91125, USA.

${ }^{3}$ Division of Chemistry and Chemical Engineering, California Institute of Technology, Pasadena, CA 91125, USA.

${ }^{4}$ Advanced Light Source, Lawrence Berkeley National Laboratory, Berkeley, CA 94720, USA

${ }^{5}$ Materials Science Division, Lawrence Berkeley National Laboratory, Berkeley, CA 94720 , USA

${ }^{6}$ Joint Center for Artificial Photosynthesis, Lawrence Berkeley National Laboratory, Berkeley, CA 94720, USA

${ }^{7}$ Beckman Institute, California Institute of Technology, Pasadena, CA 91125, USA

${ }^{8}$ State Key Laboratory of Functional Materials for Informatics, Shanghai Institute of Microsystem and Information Technology, Chinese Academy of Sciences, Shanghai 200050, China.

${ }^{9}$ School of Physical Science and Technology, ShanghaiTech University, Shanghai 200031, China.

${ }^{10}$ SUNCAT Center for Interfacial Science and Catalysis, SLAC National Accelerator Laboratory, 2575 Sand Hill Rd, Menlo Park, CA 94025, USA

${ }^{11}$ Department of Chemical Engineering, UC Berkeley, Berkeley, CA 94720, USA *Corresponding Authors. Email: lewerenz@caltech.edu, nslewis@caltech.edu

\begin{abstract}
Operando synchrotron radiation photoelectron spectroscopy (SRPES) in the tender X-ray energy range has been used to obtain information on the energy-band relations of semiconductor and metal-covered semiconductor surfaces while in direct contact with aqueous electrolytes under potentiostatic control. The system that was investigated consists of highly doped Si substrates 1
\end{abstract}


that were conformally coated with $\sim 70 \mathrm{~nm}$ titania films produced by atomic-layer deposition. The $\mathrm{TiO}_{2}$ /electrolyte and the $\mathrm{Si} / \mathrm{TiO}_{2} / \mathrm{Ni}$ electrolyte interfaces were then analyzed by synchrotron radiation photoelectron spectroscopy. The PES data provided a determination of the flat-band position and identified regions of applied potential in which Fermi level pinning, depletion, or accumulation conditions occurred. Operando X-ray absorption spectroscopy (XAS) techniques were additionally used to investigate the properties of heterogeneous electrocatalysts for the oxygen-evolution reaction. Operando XAS including the pre-edge, edge and EXAFS regions allowed the development of a detailed picture of the catalysts under operating conditions, and elucidated the changes that in the physical and electronic structure of the catalyst that accompanied increases in the applied potential. Specifically, XAS data, combined with DFT studies, indicated that the activity of the electrocatalyst correlated with the formation of $\mathrm{Fe}$ dopant sites in $\gamma-\mathrm{NiOOH}$.

\section{Introduction}

Fully integrated solar-driven water-splitting systems comprise light absorbers, catalysts and membranes [1-3]. In addition to the overpotentials associated with the anode and cathode reactions and other system losses, the thermodynamic potential needed to split water, $1.23 \mathrm{~V}$ under standard conditions, imposes constraints on the operating photovoltage produced by the light absorber. Intensive efforts have focused on transition-metal oxides (TMOs) for watersplitting applications [4-6]. An alternative approach involves dual light absorbers, analogous to the Z-scheme of natural photosynthesis [7, 8]. In such systems, two semiconductors with mutually complementary band gaps are used to increase the photovoltage at the expense of the photocurrent. A third approach combines photovoltaic tandem structures with TMOs. This latter option addresses the issue of stability that pertains to most integrated solution-contacted semiconductor structures. Other than TMOs, only a few semiconductors, including the group VI transition metal dichalcogenides [9, 10], and oxide-film protected electrodes [11-17], are stable in aqueous electrolytes.

We describe herein the use of operando ambient pressure X-ray photoelectron spectroscopy (APXPS) at the Advanced Light Source using tender X-rays in the 2 to $7 \mathrm{eV}$ region to create photoelectrons that have sufficiently long inelastic mean-free paths (IMFP) to probe the semiconductor surface; the space charge region, the adjacent Helmholtz layer, and the bulk 
electrolyte/water region [18-20]. Improving the activity of electrocatalysts composed of earthabundant elements, while achieving stability, is also of interest in the development of a stable, efficient solar-fuels generator. Accordingly, we also describe herein the use of operando highenergy-resolution fluorescence-detection X-ray absorption spectroscopy (HERFD XAS) [21], which in combination with operando EXAFS (extended X-ray absorption fine structure), enables probing of both the chemical and structural states of Ni-Fe-oxide electrocatalysts for the oxygenevolution reaction [22].

\subsection{Devices}

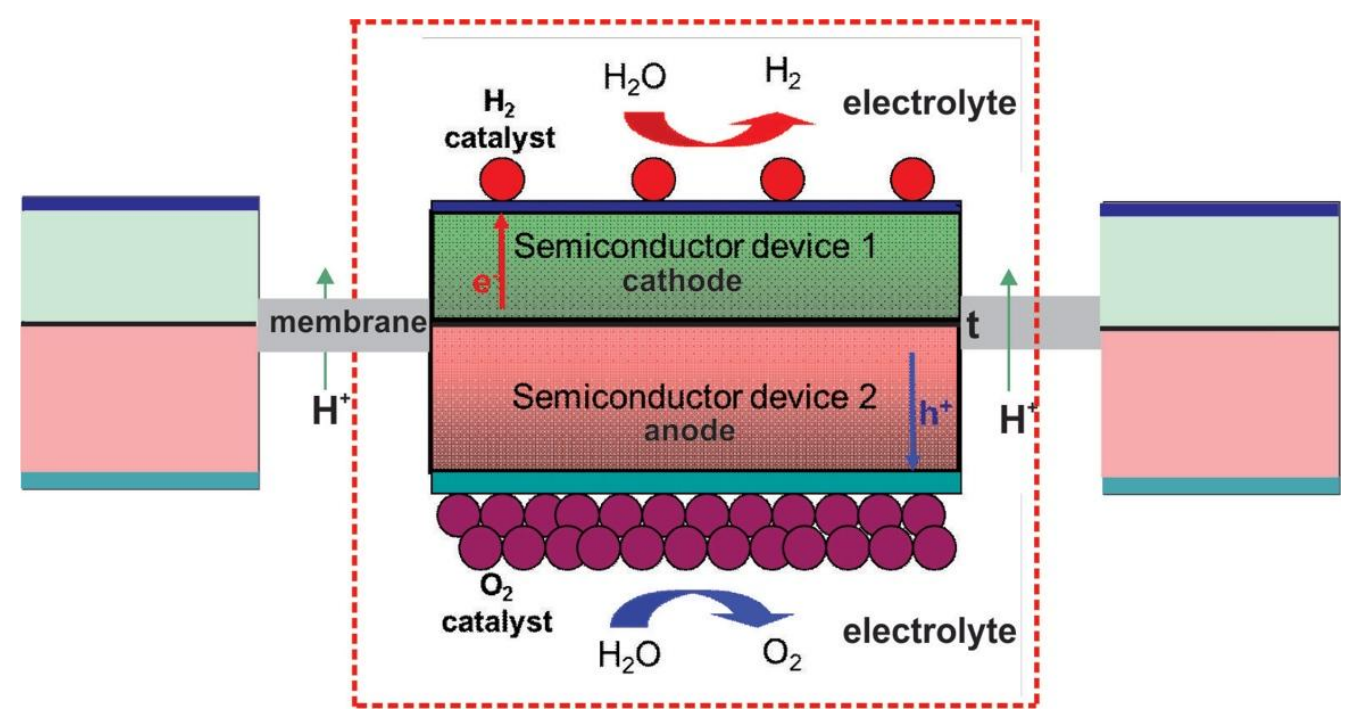

Figure 1: Cartoon of a fully integrated photoelectrochemical device for light-induced water splitting. The semiconductor devices 1 and 2 denote the two photovoltaic systems that make up the tandem cell. The two semiconductor devices have different band gaps, thus following the Zscheme of natural photosynthesis and allowing the use of a broad spectrum of light. The heterogeneous catalysts for the water splitting reactions are shown as small spheres on the top and bottom surface of the device, a tunnel junction indicated by " $t$ " electrically connects the two semiconductors devices; the blue and green thin layers between the semiconductors and catalysts are cathode and anode corrosion protection films.

Figure 1 shows a schematic of a prototypical architecture for a solar-fuels device. This arrangement has the benefits of a short transport length for charge carriers; an integrated structure that is potentially cheaper than separate photovoltaic and electrolytic units; the generation of separated products with minimal recombination; and the potential to use high- 
efficiency substructures[1]. Designs using large numbers of micro- and/or nano-dimensioned wires connected electrically in parallel hold the promise of improved stability because failure of an individual wire will not compromise the entire electrode. Recent efforts have beneficially improved the stability of technologically advanced semiconductors such as $\mathrm{Si}, \mathrm{GaAs}$, InP and $\mathrm{GaP}[11,13,23]$ in such solar fuels generator systems.

\section{Experimental}

Degenerately boron-doped $\mathrm{p}^{+}-\mathrm{Si}$ was used as a substrate for the growth of $\mathrm{TiO}_{2}$ by atomic-layer deposition (ALD). The $\mathrm{Si}$ was cleaned first with an oxidizing etch in $3: 1 \mathrm{H}_{2} \mathrm{SO}_{4}$ (98\%): $\mathrm{H}_{2} \mathrm{O}_{2}(30 \%)$ for $2 \mathrm{~min}$. The $\mathrm{Si}$ was then etched in a $10 \%$ (by volume) solution of HF for $10 \mathrm{~s}$, followed by an etch for $10 \mathrm{~min}$ at $75^{\circ} \mathrm{C}$ in a $5: 1: 1$ solution of $\mathrm{H}_{2} \mathrm{O}: \mathrm{HCl}(36 \%): \mathrm{H}_{2} \mathrm{O}_{2}$ $(30 \%)$. The $\mathrm{Si}$ was rinsed with deionized, $18.2 \mathrm{M} \Omega-\mathrm{cm}$ resistivity $\mathrm{H}_{2} \mathrm{O}$ obtained from a Millipore purification system, and was immediately transferred to the ALD deposition chamber. $\mathrm{TiO}_{2}$ was deposited by ALD in a Cambridge Nanotech Savannah reactor, using tetrakis dimethylamino titanium (IV) as the Ti precursor. The apparatus temperature was set to $150{ }^{\circ} \mathrm{C}$, and the precursor was maintained at $75^{\circ} \mathrm{C}$. A $0.1 \mathrm{~s}$ pulse of the Ti precursor was followed by a $15 \mathrm{~s}$ purge of $\mathrm{N}_{2}$ at a flow rate of $20 \mathrm{sccm}$, which was then followed by a $0.015 \mathrm{~s}$ pulse of $\mathrm{H}_{2} \mathrm{O}$ and another $15 \mathrm{~s}$ purge. This process was repeated for $\sim 1500$ cycles to give films that were $\sim 70$ nm thick. The $\mathrm{TiO}_{2}$ was amorphous and had a depletion width on the order of tens of nanometers. As appropriate, $\mathrm{Ni}$ was sputtered onto the $\mathrm{TiO}_{2}$ by use of an $\mathrm{AJA}$ - International $\mathrm{RF}$

sputtering system, with a sputtering rate of $\sim 2 \mathrm{~nm} \mathrm{~min}^{-1}$ in an Ar atmosphere. The electrode was assembled by making an ohmic contact to the back of the Si wafer with $\mathrm{In} / \mathrm{Ga}$ eutectic. Ag paint was then used to affix the electrode to a $\mathrm{Cu}$ foil, and the back and sides of the electrode were encased with non-conductive, Hysol 9460 epoxy.

Operando APXPS data were collected at beamline 9.3.1 at the Advanced Light Source. $\mathrm{p}^{+}-\mathrm{Si} / \mathrm{TiO}_{2}$ as well as $\mathrm{p}^{+}-\mathrm{Si} / \mathrm{TiO}_{2} / \mathrm{Ni}$ electrodes, with $\mathrm{Ni}$ thicknesses in the range of 0.5 to $10 \mathrm{~nm}$, were contacted with $1.0 \mathrm{M} \mathrm{KOH}(\mathrm{aq})$ by use of the "dip and pull" method [18-20]. Operando APXPS data were collected while the electrode was under potential control between $-1.4 \mathrm{~V}$ and $+0.4 \mathrm{~V}$ vs $\mathrm{Ag} / \mathrm{AgCl}$. Potentials were applied and maintained by a Biologic SP-300 potentiostat. 
A photon energy of $4 \mathrm{keV}$ was used from a range of $2.3-5.2 \mathrm{keV}$, with an energy resolution of $\mathrm{E} / \Delta \mathrm{E}=3000-7200$.

For HERFD X-ray absorption spectroscopy (XAS), electrodes were prepared on a $10 \mathrm{~nm}$ thin Au electrode backed by a $1 \mu \mathrm{m}$ thick Si nitride membrane window with a $4 \mathrm{~nm}$ thick $\mathrm{Ti}$ adhesion layer. $\mathrm{Ni}$ and $\mathrm{Fe}$ were deposited from $\mathrm{FeSO}_{4}$ and $\mathrm{NiSO}_{4}$ precursor solutions, respectively [24]. Operando HERFD XAS data were collected at beamline 6-2 at the Stanford Synchrotron Light Source (SSRL). Extended X-ray absorption fine structure (EXAFS) data were collected at beamline 4-1 at the SSRL.

(a)

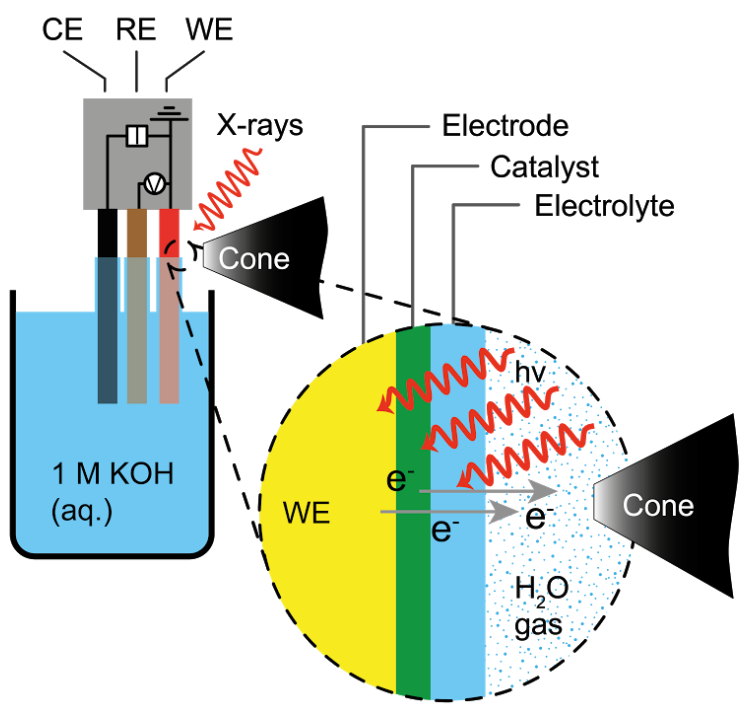

(b)

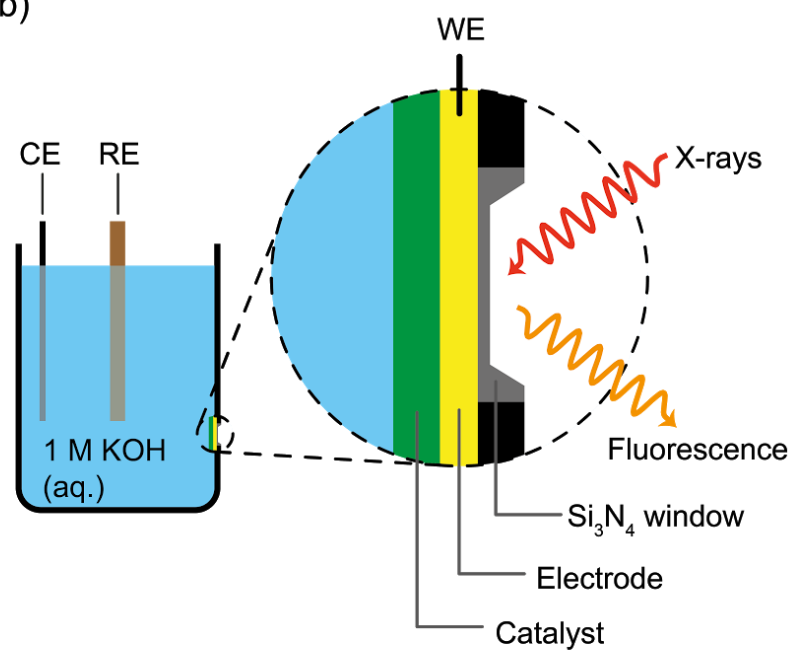

Figure 2: Schematic illustration of the operando AP-XPS (a) and operando high energy resolution fluorescence detection (HERFD) X-ray absorption spectroscopy (XAS) (b) setup. In both cases the potential $U$ is applied to the working electrode using a three electrode configuration. In (a) working electrode and analyzer are grounded to equalize the Fermi energy between both. For operando APXPS the sample is illuminated by X-rays through the front (electrolyte) as well photoelectrons are the photoelectrons collected through the front. For XAS the working electrode is illuminated by X-rays through the back (ultrathin substrate and $\mathrm{Si}_{3} \mathrm{~N}_{4}$ window) as well are the scattered $X$-ray photons collected through the back.

Fig. 2 shows a general schematic of (a) the operando APXPS sampling geometry, and (b) the HERFD sampling geometry, at the relevant beamline endstations. Fig. 3 indicates the energetic relations under investigation in the semiconductor/liquid junction operando APXPS 
experiment. Binding energies referenced to the Fermi Level of the working electrode and analyzer are labelled $\mathbf{E}_{\mathrm{B}}$ and kinetic energies also measured from the Fermi Level of the working electrode are defined as $\mathbf{E}_{\mathrm{K}}$. A core level (CL) energy and the Helmholtz double layer (HDL) are shown, in addition to the work functions $(\phi)$ of the materials of interest. 


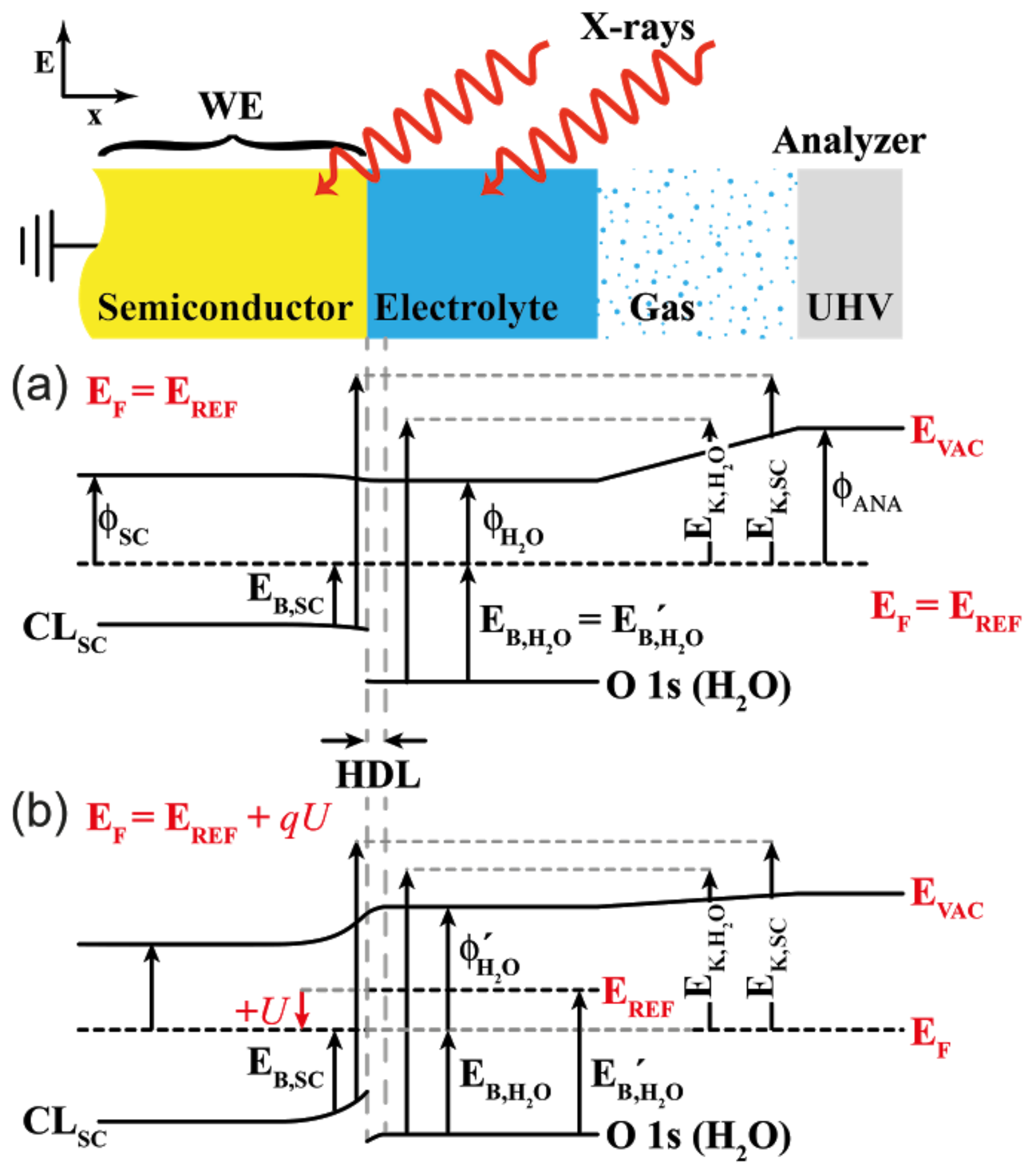

Figure 3: Operando APXPS energy relations diagram of a semiconductor/liquid junction without applied bias (a) and with an applied bias $U$ relative to a reference electrode $E_{R E F}$. The potential $U$ is applied between the reference potential $E_{R E F}$ and the Fermi Energy $E_{F}$ of the semiconductor. The binding energy of the core levels is given with respect to $E_{F}$. The difference 
between Vacuum level and Fermi energy is determined by the work function $\phi$. The analyzer and working electrode are grounded, i.e. their Fermi Energies are equalized. The potential can drop in the semiconductor and/or in the Helmholtz double layer (HDL) of the electrolyte. Oriented water in the HDL as well as surface ionic charges may influence the near-surface energetics of the liquid, but the technique primarily focuses on the bulk quantities in $1 M$ electrolyte concentration ranges.

\section{Results and discussion}

\subsection{Operando APXPS}

Operando APXPS studies of a semiconductor/liquid junction depend on the inelastic mean-free path (IMFP) of photoelectrons ejected by the incident X-rays, as well as on the photoionization cross section for the process (Fig. 3). Fig. 4 shows the IMFP and the photoionization cross section, respectively, as a function of the incident photon energy. The IMFP, which correlates directly with the probing depth, was calculated using IMFP-TPP2M [25]. Higher photon energies correlate with greater sampling depths, but produce lower signal intensities due to smaller photoionization cross sections. Table 1 lists the IMFPs through various materials for $\mathrm{Ni} 2 \mathrm{p}$, Ti $2 \mathrm{p}$, and $\mathrm{O}$ 1s core-level photoelectrons that originate from a $4 \mathrm{keV}$ X-ray source.

(a)

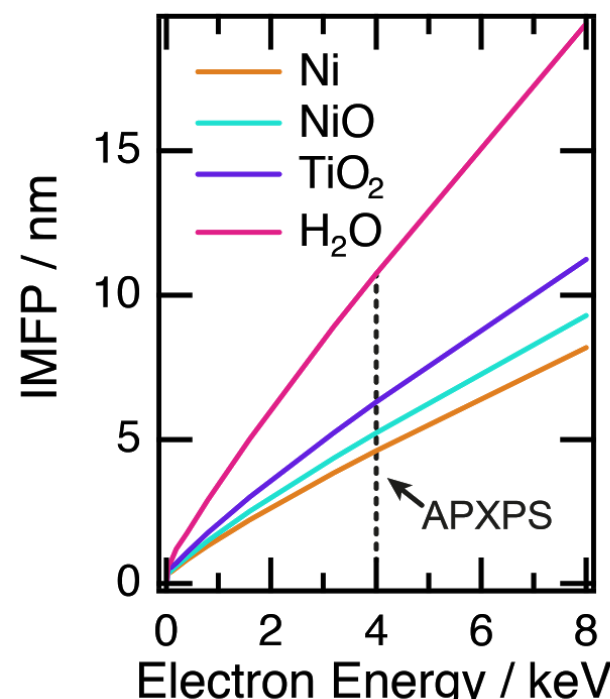

(b)

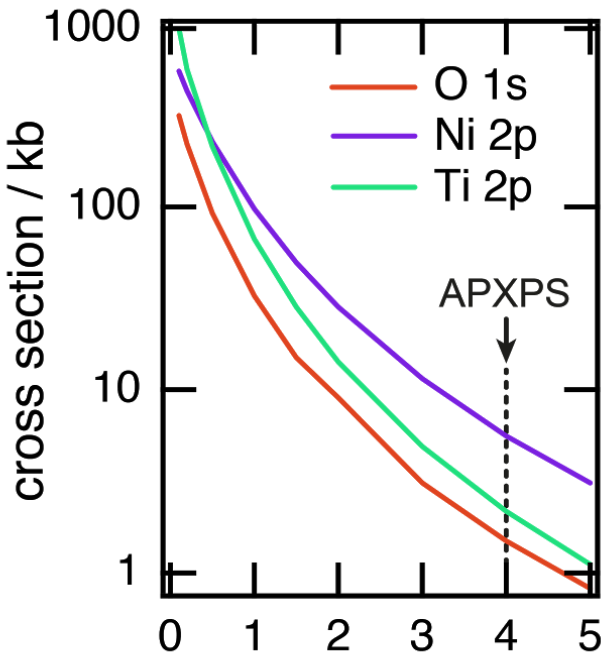

Electron Energy / keV

Figure 4: Dependence of the photoelectron inelastic mean free path (IMPF) and the core level photoionization cross section on the electron energy [25, 26]. The IMFP is given in nm and 
cross section is given in kilo barns $\left(1 \mathrm{~kb}=10^{-25} \mathrm{~m}^{2}\right)$. The IMFP increases with electron energy whereas the cross section decreases. Thus, to probe the solid/liquid interface, the optimal photon energy shifts slightly to higher energies as the electrolyte thickness increases. $4 \mathrm{keV}$ was therefore used for the operando APXPS experiments [27], as indicated by the dashed line.

(a)

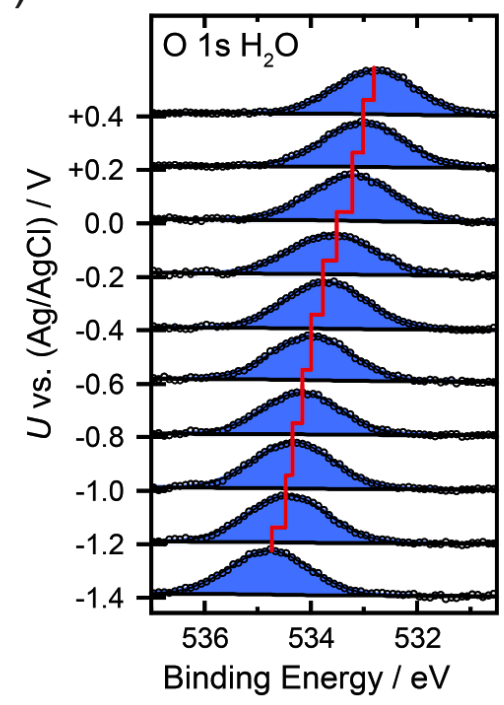

(b)

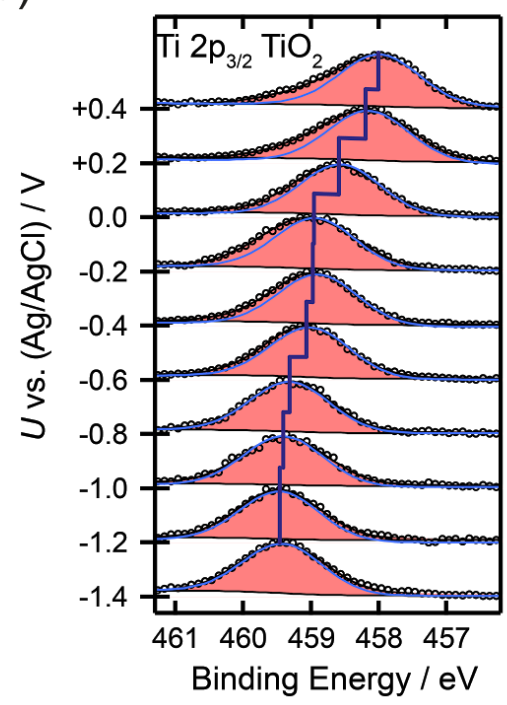

(c)

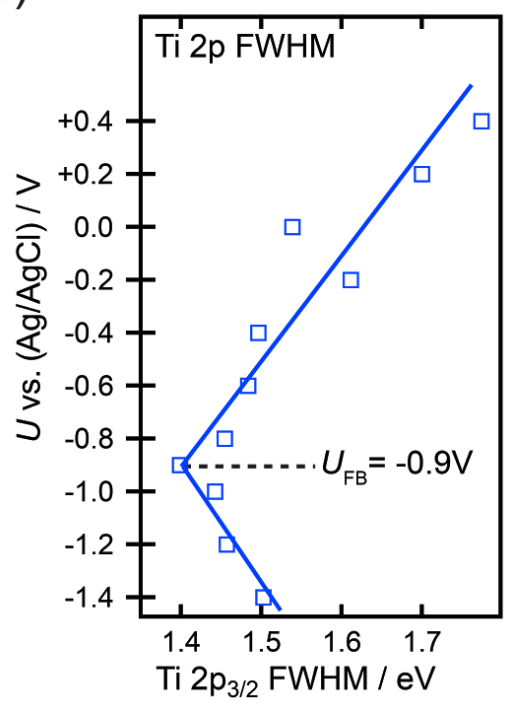

Figure 5: Operando APXPS O $1 \mathrm{~s}$ (of $\mathrm{H}_{2} \mathrm{O}$ ) and $\mathrm{Ti} 2 p_{3 / 2}$ (of $\mathrm{TiO}_{2}$ ) core level spectra of the $\mathrm{TiO}_{2}$ /electrolyte interface at applied potential $U$. The blue curve in (b) shows the Ti $2 p_{3 / 2}$ line shape at $U_{F B}$ indicating the additional peak broadening for potentials more negative or positive than $U_{F B}$. (c) Dependence of the full width at half maximum $(F W H M)$ of the Ti $2 p_{3 / 2}$ core level on the applied potential for the $\mathrm{TiO}_{2} /$ electrolyte interface. The FWHM has a minimum at the flatband potential. The Nernstian potentials for HER and OER at pH 14 are $-1.026 \mathrm{~V} v \mathrm{~s} \mathrm{Ag} / \mathrm{AgCl}$ and $.204 \mathrm{~V}$ vs $\mathrm{Ag} / \mathrm{AgCl}$, respectively.

Fig. 5(a) depicts the signals from the $\mathrm{O}$ 1s core level from $\mathrm{H}_{2} \mathrm{O}$ for a $\mathrm{p}^{+}-\mathrm{Si} / \mathrm{TiO}_{2}$ electrode in $1.0 \mathrm{M} \mathrm{KOH} \mathrm{(aq).} \mathrm{The} \mathrm{binding} \mathrm{energies} \mathrm{are} \mathrm{plotted} \mathrm{with} \mathrm{respect} \mathrm{to} \mathrm{the} \mathrm{Fermi} \mathrm{energy} \mathrm{of} \mathrm{the}$ electrode, which was in contact with (i.e., grounded to) the analyzer. Fig. 5(b) plots the observed signals of the $\mathrm{Ti} 2 \mathrm{p}_{3 / 2}$ photoemission from the $\mathrm{TiO}_{2}$. The core level for $\mathrm{Ti} 2 \mathrm{p}_{3 / 2}$ at each potential contains a trace indicating the shape of the peak at the flat-band potential. At potentials other than the flat-band potential, the peak width increases due to band bending. Fig. 5(c) shows the correlation of peak width for the $\mathrm{Ti} 2 \mathrm{p}_{3 / 2}$ core level with applied potential for the $\mathrm{TiO}_{2} /$ electrolyte 
system. Further equations and models derived from such data [28] are presented below. Fig. 6 depicts the energy of the Ni $2 \mathrm{p}$ core level, $\mathbf{E}_{\mathrm{B}, \mathrm{Ni}}$, from operando APXPS data, for a $\mathrm{p}^{+}-\mathrm{Si} / \mathrm{TiO}_{2} / \mathrm{Ni}$ electrode in $1.0 \mathrm{M} \mathrm{KOH}(\mathrm{aq})$.

Table 1: Mean free path of $\mathrm{Ni} 2 \mathrm{p}, \mathrm{Ti} 2 \mathrm{p}$ and $\mathrm{O} 1 \mathrm{~s}$ core levels at the optimal photon energy of $4 \mathrm{keV}$ in different materials. The photoelectron energy of the core levels used in this work is given in brackets. IMFPs were calculated by IMFP-TPP2M. The "Core level" column indicates from which core level a photoelectron would originate with a given kinetic energy, while the "material" column indicates the material for which the given IMFP is accurate for such a photoelectron. A photoelectron from $\mathrm{TiO}_{2}$ in a $\mathrm{TiO}_{2} /$ Ni/electrolyte sample would necessarily have to travel through $\mathrm{TiO}_{2}, \mathrm{Ni}$, and $\mathrm{H}_{2} \mathrm{O}$, so all such escape depths are provided.

\begin{tabular}{|l|l|c|}
\hline Material & Core level & Inelastic mean free path (nm) \\
\hline $\mathbf{T i O}_{\mathbf{2}}$ & Ti 2p $(3540 \mathrm{eV})$ & 5.597 \\
\hline \multirow{2}{*}{$\mathbf{N i}$} & O 1s $(3466 \mathrm{eV})$ & 5.501 \\
\hline & Ti 2p $(3540 \mathrm{eV})$ & 4.165 \\
\hline & O 1s $(3466 \mathrm{eV})$ & 4.094 \\
\hline $\mathbf{H}_{\mathbf{2}} \mathbf{O}$ & Ni 2p $(3145 \mathrm{eV})$ & 3.785 \\
\hline & Ti 2p $(3540 \mathrm{eV})$ & 9.691 \\
\hline & O 1s $(3466 \mathrm{eV})$ & 9.520 \\
\hline
\end{tabular}




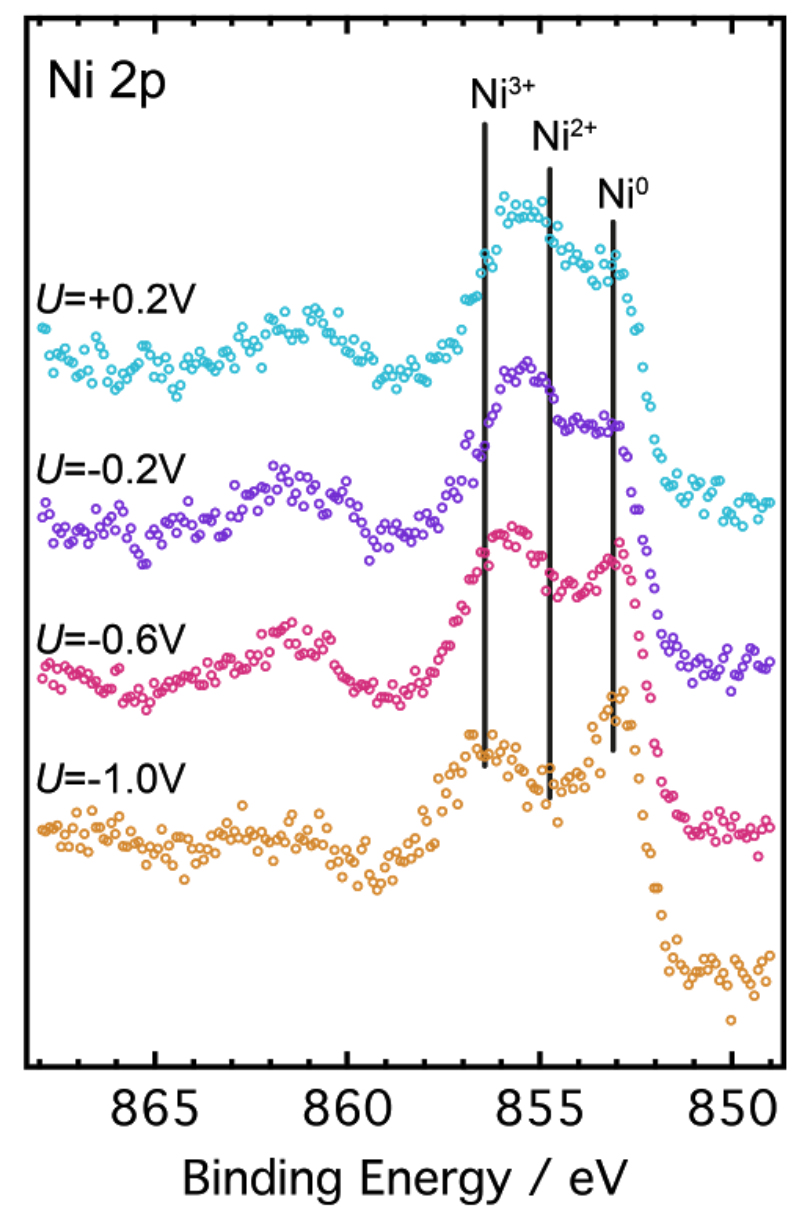

Figure 6: Raw data of Ni $2 p$ core levels obtained by operando APXPS at different applied potential $U$ of a $\mathrm{Ni} / \mathrm{HHL} / \mathrm{electrolyte}$ interface. The peak positions of the metallic Nickel $\left(\mathrm{Ni}^{0}\right)$ the Nickel oxide $\left(\mathrm{Ni}^{2+}\right.$ and $\left.\mathrm{Ni}^{3+}\right)$ are indicated.

We first consider the operando APXPS results in Figs. 5 and 6, in conjunction with the schematic in Fig. 3, in the context of the IMFP and the excitation cross section (Fig.4 and table 1) data and including the evaluation of the peak FWHM in Fig. 5(c). Fig. 7 summarizes the behavior of the core-level lines as a function of the applied potential for $\mathrm{TiO}_{2}, \mathrm{TiO}_{2} / \mathrm{Ni}$ and bulk $\mathrm{H}_{2} \mathrm{O}$.

Two types of electrodes were investigated: "bare" $\mathrm{TiO}_{2}$, in which $\mathrm{ALD}$-deposited $\mathrm{TiO}_{2}$ was grown on metallic $\mathrm{Si}\left(\mathrm{p}^{+}-\mathrm{Si} / \mathrm{TiO}_{2}\right)$, and a $\mathrm{p}^{+}-\mathrm{Si} / \mathrm{TiO}_{2}$ electrode that was capped by sputterdeposited $\mathrm{Ni}\left(\mathrm{p}^{+}-\mathrm{Si} / \mathrm{TiO}_{2} / \mathrm{Ni}\right)$, to produce a thin layer of the electrocatalyst film. For the $\mathrm{p}^{+}-$ $\mathrm{Si} / \mathrm{TiO}_{2}$ electrode, in accumulation, a negative applied potential shifts the Fermi level position 
closer to the conduction band than the energy that is given by the doping level alone. In this case, electron accumulation occurs at the surface and, depending on the amount of negative polarization, a two-dimensional electron gas can be formed. As the Fermi level approaches the conduction band, high electron concentrations occur at the interface and the band bending in the semiconductor becomes fixed. More negative applied biases will not result in more band bending in the semiconductor, but instead give rise to a potential drop across the compact HDL and produce band-edge shifts in the semiconductor relative to the bulk solution chemical potential. Thus $\mathbf{E}_{\mathrm{B}, \mathrm{TiO} 2}\left(=\mathrm{E}_{\mathrm{F}}-\mathrm{E}_{\mathrm{CL}, \mathrm{TiO} 2}\right.$, Fig 3) does not change with $U_{\text {applied }}$ for $U_{\text {applied }}<-1.0 \mathrm{~V}$ in Fig. 5, indicated by the red portion of the line for $\mathbf{E}_{\mathrm{B}, \mathrm{TiO} 2}$ in Fig. 7 (cathodic). At applied potentials moderately positive of the flat-band potential, $\underline{U}_{\text {applied }}>U_{\mathrm{FB}}, \mathbf{E}_{\mathrm{B}, \mathrm{TiO} 2}$ changes linearly with applied potential, with a slope close to $1 \mathrm{eV} \mathrm{V}^{-1}\left(\mathrm{dE}_{\mathrm{B}, \mathrm{TiO} 2} / \mathrm{d} U_{\text {applied }}\right)$. The semiconductor behaves ideally, with changes in the Fermi level resulting in changes in band bending in the semiconductor. Thus the difference between the Fermi level of the semiconductor and the position of the core levels at the semiconductor surface decreases as the potential is made more positive. This behavior is shown by the leftmost black part of the $\mathbf{E}_{\mathrm{B}, \mathrm{TiO} 2}$ line. At yet more positive potentials, the core level lines again become independent of the applied voltage, depicted by the second red portion of the $\mathbf{E}_{\mathrm{B}, \mathrm{TiO} 2}$ line. This behavior can be attributed to Fermi level pinning, in which a high density of surface or defect states defines the band bending in the semiconductor. Depending on the density of these states, partial or full Fermi level pinning (FLP) can occur $[29,30]$. In the latter, as observed herein, increasingly positive potentials do not result in an increase in the semiconductor band bending, and $\mathbf{E}_{\mathrm{B}, \mathrm{TiO} 2}$ is independent of $U_{\text {applied }}$ (Fig. 5). Beyond this potential range, the semiconductor becomes unpinned, and the change of $\mathbf{E}_{\mathrm{B}, \mathrm{TiO} 2}$ with $U_{\text {applied }}$ is again close to $1 \mathrm{eV} \mathrm{V}^{-1}$, again shown with a black line. These results add depth to the various investigations of mid-gap states in titania films [31, 32]. 


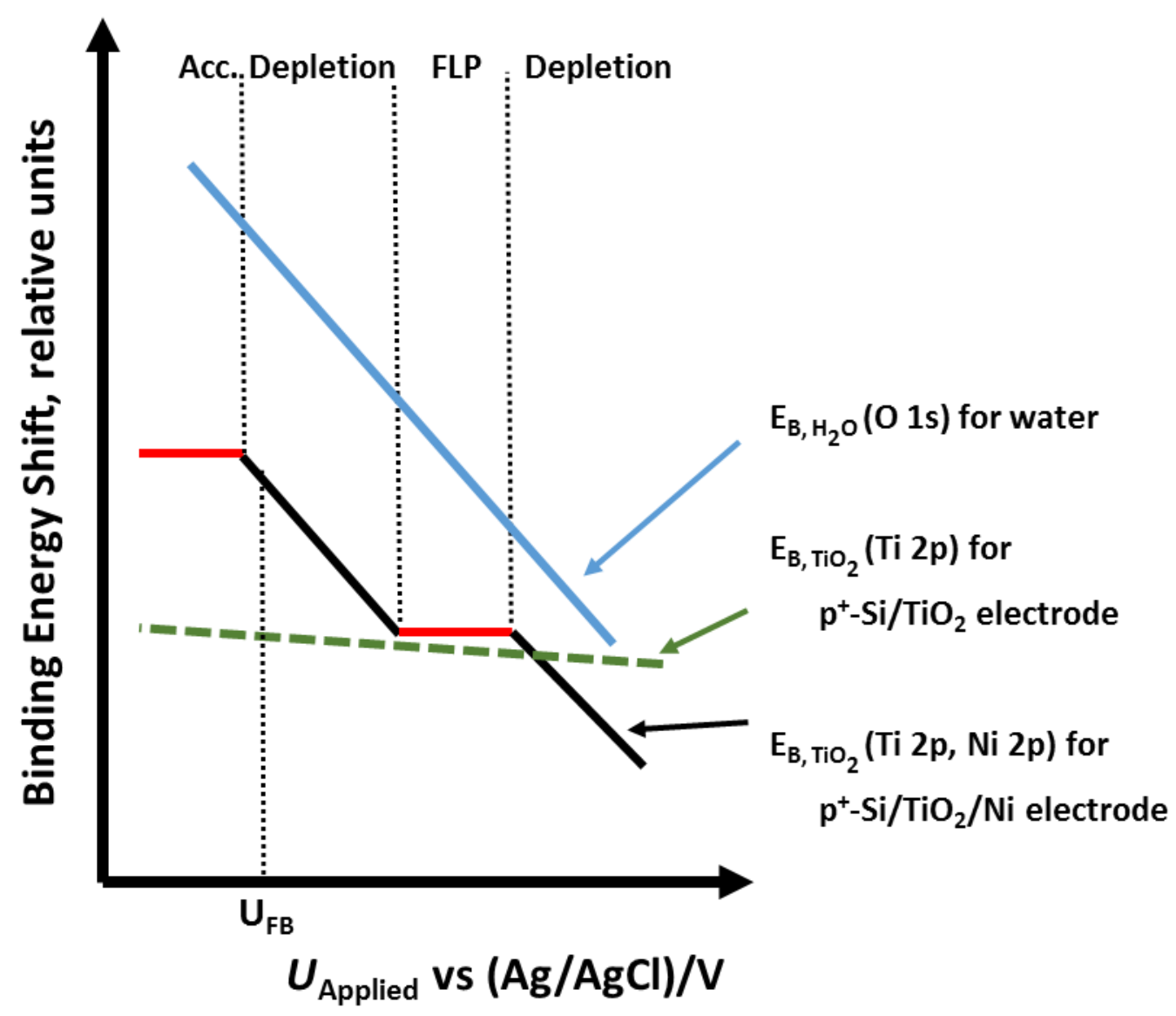

Figure 7: Evaluation of the behavior of various samples and components with applied potential as indicated; data are extracted from Figs. 5,6 (see text). Regions for accumulation, depletion and Fermi level pinning (FLP) are indicated. Red regions indicate band-edge shifts. The Ti core levels denote the semiconductor/liquid junction behavior with Fermi-level pinning for a bare $\mathrm{TiO}_{2}$ electrode, but the addition of $\mathrm{Ni}$ results in $\mathrm{Ni}$ and Ti core levels that are effectively constant with respect to applied potential, and thus are seen to have metallic character.

The $\mathrm{O}$ 1s line of bulk water in contact with a p $\mathrm{p}^{+}-\mathrm{Si} / \mathrm{TiO}_{2}$ electrode, plotted in Figs. 5 and 7 (blue line), shows ideal behavior, i.e. a slope of $1 \mathrm{eV} \mathrm{V}^{-1}$. The applied potential drops across the semiconductor (band bending) or in the electrolyte double layer (HDL) which, in the high concentration electrolyte solutions used here, is a compact Stern-type layer of $\sim 1 \mathrm{~nm}$ thickness. Thus, with the working electrode (sample) in contact with the instrument ground, and with $\mathbf{E}_{\mathrm{B}, \mathrm{H} 2 \mathrm{O}}$ measured with respect to the Femi level of the sample, the bulk solution levels shift with the applied potential. 
A surface covered with metallic $\mathrm{Ni}\left(\mathrm{p}^{+}-\mathrm{Si} / \mathrm{TiO}_{2} / \mathrm{Ni}\right.$, Figs. 6 and 7) behaves similarly to a metal-semiconductor-electrolyte or to a pure metal-electrolyte junction (green dashed line), for which $\mathbf{E}_{\mathrm{B}}$ of the metal should be independent of the applied potential. While $\mathbf{E}_{\mathrm{B}, \mathrm{Ni}}$ was not fully independent of the applied potential, the small slope suggests that the applied potential drops almost exclusively at the metal-electrolyte interface, i.e. in the HDL. The small change with $U_{\text {applied }}$ indicates that uncovered surface areas may exist, producing a mixed barrier-height system in accord with expectations for pinch-off effects[33].

The intensity of emitted photoelectrons decays exponentially with the sampling depth, with an attenuation constant given by the IMFP (Fig. 4a). $95 \%$ of the intensity of a core-level emission peak therefore originates within a depth of three times the IMFP. The band bending of core levels of a semiconductor with respect to the Fermi level is a function of both depth and potential; at flat band, the binding-energy peak has a minimal FWHM. However, in the presence of band bending, the energy peak represents an average value due to the changing binding energies within the sampling depth producing a peak width characteristic of the band bending. Thus at the flat-band potential, $U_{\mathrm{FB}}$, the observed FWHM will have a minimum value and the width will increase for potentials more positive or negative than $U_{\mathrm{FB}}$ (see Fig. 6c) [28].

\subsection{XAS}

Fig. 8 presents XAS data for Ni-Fe-oxide catalysts on a Au electrode. Fig. 8(a) shows HERFD XAS measurements at the Ni K-edge for $\mathrm{NiO}_{\mathrm{x}} \mathrm{H}_{\mathrm{y}}$, whereas Fig. 8(b) shows data at the Fe K-edge for a series of $\mathrm{Ni}_{u} \mathrm{Fe}_{v} \mathrm{O}_{\mathrm{x}} \mathrm{H}_{\mathrm{y}}$ samples that had different Fe/Ni ratios. The HERFD spectra can be divided in three regions: the weak pre-edge region with features arising from $1 \mathrm{~s} \rightarrow 3 \mathrm{~d}$ transitions; the main absorption edge region; and the oscillatory fine structure region that begins $\sim 25 \mathrm{eV}$ above the main-edge inflection point. The predominant contributions to these three spectral regions are: energy shifts of pre-edge peaks and of the onset of the main edge attributed to metal oxidation state changes; pre-edge intensities and multiplicities, which, together with peak shapes just above the main edge, correlate with the local symmetry at the absorber atom; and the oscillatory structure at high energies, predominantly due to singlescattering of photoelectrons that can be described within the theoretical framework of EXAFS and is correlated with the radial distribution of neighbor atoms within $\sim 0.5-0.6 \mathrm{~nm}$ of the absorber atom. While the EXAFS energy range obtained from HERFD XAS data is too narrow 
to allow fitting by several independent sets of interatomic distances and coordination numbers, the spectra of the particular Ni-Fe systems shown here are suitable for a "bond length with a ruler" analysis, which is equivalent to an EXAFS analysis using only two independent parameters: strain for uniform compression of all interatomic distances, and the oxidation-state sensitive photoemission threshold energy.

Each of the Fe and Ni K-edge spectra, which were acquired for Ni/Fe ratios from 100:0 to $0: 100$, can be described as a linear combination of the same two spectral components that were obtained from the measurements of a Ni/Fe (75:25) sample at $1.12 \mathrm{~V}$ and $1.62 \mathrm{~V}$ vs RHE (reversible hydrogen electrode), respectively. For these two conditions, full EXAFS was measured using conventional fluorescence detection. For the EXAFS measurements, a $10 \mathrm{~nm}$ thick $\mathrm{Ni}_{75} \mathrm{Fe}_{25} \mathrm{O}_{\mathrm{x}} \mathrm{H}_{\mathrm{y}}$ sample was prepared by sputter co-deposition of $\mathrm{Ni}$ and $\mathrm{Fe}$, followed by electrochemical oxidation in $0.1 \mathrm{M} \mathrm{KOH}(\mathrm{aq})$. The resulting electrocatalyst did not contain metallic Ni or Fe, and EXAFS measurements at $1.12 \mathrm{~V}$ vs RHE showed the short-range ordering of $\mathrm{a} \mathrm{Ni}^{2+}-\mathrm{Fe}^{3+}$ layered double hydroxide (LDH). The LDH structure has in common with $\alpha-$ $\mathrm{Ni}(\mathrm{OH})_{2}$ the characteristic that sheets of edge-sharing $\left[\mathrm{NiO}_{6}\right]$ octahedra are stacked with $\mathrm{H}_{2} \mathrm{O}$ molecules intercalated between the sheets. In $\mathrm{NiFe}-\mathrm{LDH}, \mathrm{Fe}^{3+}$ cations substitute for $\mathrm{Ni}^{2+}$ cations, and the resulting additional positive charge in the sheets is balanced by electrolyte anions intercalated between the sheets. For an electrode potential of $1.12 \mathrm{~V}$ vs RHE, the EXAFS Fourier transform (Fig. 8(c)) exhibited two strong peaks, at $\sim 0.16 \mathrm{~nm}$ and $\sim 0.28 \mathrm{~nm}$, respectively, corresponding to six-fold coordination of $\mathrm{Fe}$ and $\mathrm{Ni}$ cations with $\mathrm{O}$ and metal neighbors (Fe or $\mathrm{Ni}$ ), respectively.

A strong multiple-scattering contribution to the peak at $\sim 0.57 \mathrm{~nm}$ was also observed, and indicates a collinear arrangement of three metal $(\mathrm{Ni}, \mathrm{Fe})$ cations. This result confirms the location of the metal cations within the hexagonal sheets. This multiple-scattering feature had the same intensity in the Fe spectra as in the Ni spectra, consistent with expectations that the Fe cations substitute for $\mathrm{Ni}$ within the sheets, as opposed to intercalating between the sheets.

A comparison of the EXAFS measurements at electrode potentials of 1.12 and $1.62 \mathrm{~V}$ vs RHE indicates that an increase in the potential produced a contraction of the interatomic distances (Table 2). All of the metal-metal nearest-neighbor distances (NNDs) decreased by $8.7 \%$, and the $\mathrm{Ni}-\mathrm{O}$ and $\mathrm{Fe}-\mathrm{O}$ bonds contracted by $8.3 \%$ and $5.5 \%$, respectively. Notably, the metal-metal NNDs were identical for Fe and Ni, within $\pm 0.002 \mathrm{~nm}$, before $(0.310 \mathrm{~nm})$ and after 
$(0.283 \mathrm{~nm})$ oxidation. Identical $\mathrm{Ni}-\mathrm{O}$ and $\mathrm{Fe}-\mathrm{O}$ bond lengths $(0.189 \pm 0.002 \mathrm{~nm})$ were also measured at an electrode potential of $1.62 \mathrm{~V}$ vs RHE. The larger bond length difference between $\mathrm{Ni}-\mathrm{O}(0.206 \mathrm{~nm})$ and $\mathrm{Fe}-\mathrm{O}(0.201 \mathrm{~nm})$ at $1.12 \mathrm{~V}$ vs RHE can be explained by different local distortions of $\mathrm{MO}_{6}$ units from ideal octahedral symmetry.
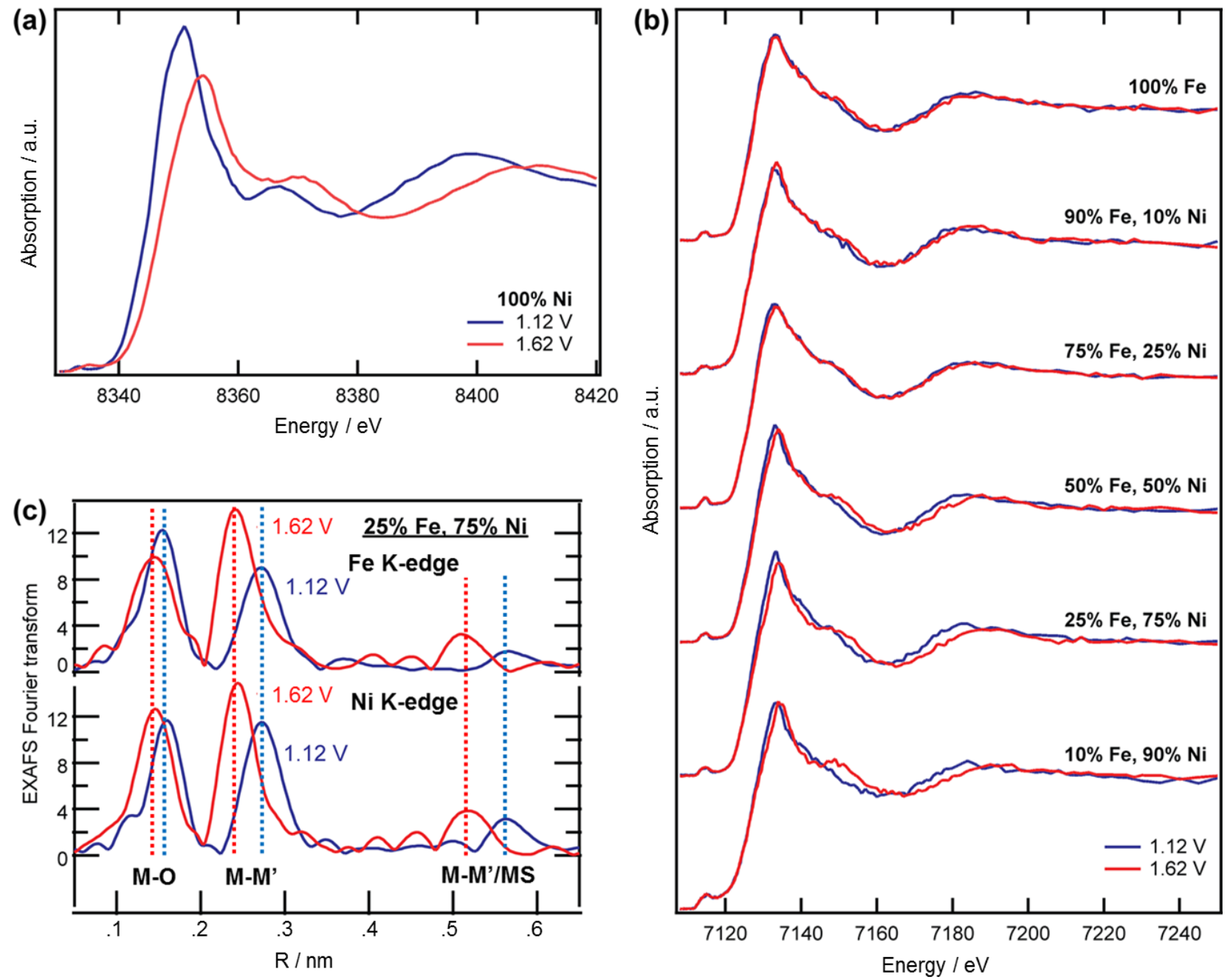

Figure 8: HERFD XAS and EXAFS of Ni-Fe-oxide catalysts: HERFD spectra of the Ni and the $\mathrm{Fe}$ K-edge for pure oxide catalysts of only $\mathrm{Ni}(\mathrm{a})$ and for $25 \% \mathrm{Fe}$ content in $\mathrm{Ni}(\mathrm{b})$, (c) Fourier transformation of EXAFS data; M-O: metal-oxide distance; M-M': metal-metal nearestneighbor distance; M-M'/MS: mixed single-and multiple-scattering contributions in linear M$M$ '-M' arrangement. Voltages for this section are relative to RHE; the thermodynamic OER potential is $1.23 \mathrm{~V}$ vs RHE. 
HERFD XAS was the preferred method to obtain electronic structure information on this system, because the partial removal of core-hole lifetime broadening in HERFD XAS allows for higher resolution and a better separation of the oxidation-state sensitive pre-edge features from the main-edge than in conventional XAS. At the Ni K-edge, HERFD spectra of a $100 \% \mathrm{Ni}$ sample reveal the well-known spectral features of $\alpha-\mathrm{Ni}(\mathrm{OH})_{2}$ and of $\gamma-\mathrm{NiOOH}$ at $1.12 \mathrm{~V}$ and $1.62 \mathrm{~V}$, respectively. Independent of the $\mathrm{Ni}: \mathrm{Fe}$ ratio, at $1.12 \mathrm{~V}$, all $\mathrm{Ni}$ cations were present as $\mathrm{Ni}^{2+}$ in $\alpha-\mathrm{Ni}(\mathrm{OH})_{2}$ or a layered $\mathrm{Ni}^{2+}-\mathrm{Fe}^{3+}$ double hydroxide. Conventional in situ XAS measurements on the $\alpha-\mathrm{Ni}(\mathrm{OH})_{2} / \gamma-\mathrm{NiOOH}$ conversion[34-38] are in good agreement with the data collected herein. At $1.62 \mathrm{~V}$ vs RHE, the Ni pre-edge and the main absorption edge shift, indicative of the oxidation of $\mathrm{Ni}^{2+}$ to $\mathrm{Ni}^{3+/ 4+}$. These changes in oxidation state are in agreement with the changes in the $\mathrm{Ni}-\mathrm{O}$ distances observed in the EXAFS data described above. At $1.62 \mathrm{~V}$, at least $90 \%$ of the $\mathrm{Ni}$ was oxidized to $\mathrm{Ni}^{3+/ 4+}$ cations in the pure $\mathrm{Ni}$ or Fe-doped $\gamma-\mathrm{NiOOH}$.

Table 2. Summary of EXAFS results

\begin{tabular}{|c|c|c|c|c|}
\hline & \multicolumn{2}{|c|}{ Ni K-edge } & \multicolumn{2}{|c|}{ Fe K-edge } \\
\hline$E=1.12 \mathrm{~V}$ & $\mathrm{Ni}-\mathrm{O}$ & $\mathbf{N i}-\mathbf{N i}$ & $\mathbf{F e}-\mathbf{O}$ & Fe-Ni \\
\hline $\mathrm{CN}$ & $6.5 \pm 0.6$ & $5.5 \pm 0.6$ & $6.5 \pm 0.6$ & $5.9 \pm 0.7$ \\
\hline Distance (nm) & $0.206 \pm 0.001$ & $0.310 \pm 0.001$ & $0.201 \pm 0.001$ & $0.310 \pm 0.001$ \\
\hline \multirow[t]{3}{*}{$\sigma^{2}\left(\mathrm{~nm}^{2}\right)$} & 0.00005 & 0.00005 & 0.00005 & 0.00007 \\
\hline & $\begin{array}{r}k \text {-range: } \\
r \text { range: } 0 \\
\mathrm{R} \text { fa } \\
E_{0}=(-1\end{array}$ & $\begin{array}{l}117 \mathrm{~nm}^{-1} \\
\text { to } 0.34 \mathrm{~nm} \\
0.05 \\
1.9) \mathrm{eV}\end{array}$ & $\begin{array}{r}k \text {-range: } 2 \\
r \text { range: } 0 \\
\mathrm{R} \text { fac } \\
E_{0}=(-1\end{array}$ & $\begin{array}{l}\text { to } 115 \mathrm{~nm}^{-1} \\
\text { to } 0.35 \mathrm{~nm} \\
0.015 \\
\pm 1.8) \mathrm{eV}\end{array}$ \\
\hline & \multicolumn{2}{|c|}{ Ni K-edge } & \multicolumn{2}{|c|}{ Fe K-edge } \\
\hline$E=1.62 \mathrm{~V}$ & $\mathrm{Ni}-\mathrm{O}$ & $\mathbf{N i - N i}$ & Fe-O & Fe-Ni \\
\hline $\mathrm{CN}$ & $6.1 \pm 0.9$ & $5.4 \pm 0.7$ & $5.4 \pm 0.9$ & $5.2 \pm 0.7$ \\
\hline Distance (nm) & $0.189 \pm 0.002$ & $0.282 \pm 0.001$ & $0.190 \pm 0.002$ & $0.284 \pm 0.002$ \\
\hline \multirow{2}{*}{$\sigma^{2}\left(\mathrm{~nm}^{2}\right)$} & 0.00005 & 0.00005 & 0.00005 & 0.00005 \\
\hline & $\begin{array}{r}k \text {-range: } \\
r \text { range: } 0 \\
\mathrm{R} \text { fac } \\
E_{0}=(-2\end{array}$ & $\begin{array}{l}117 \mathrm{~nm}^{-1} \\
\text { to } 0.30 \mathrm{~nm} \\
0.094 \\
2.4) \mathrm{eV}\end{array}$ & $\begin{array}{r}k \text {-range: } 2 \\
r \text { range: } 0 \\
\mathrm{R} \text { fac } \\
E_{0}=(-4\end{array}$ & $\begin{array}{l}\text { to } 115 \mathrm{~nm}^{-1} \\
\text { to } 0.30 \mathrm{~nm} \\
0.028 \\
\pm 2.9) \mathrm{eV}\end{array}$ \\
\hline
\end{tabular}

At an electrode potential of $1.12 \mathrm{~V}$ vs RHE, the Fe K-edge spectra were consistent with $\mathrm{Fe}^{3+}$ cations in an octahedral environment, with $\mathrm{Fe}-\mathrm{O}$ bond lengths typical for $\mathrm{FeOOH}$ or $\mathrm{Ni}-\mathrm{Fe}$ double hydroxide. During OER conditions at $E=1.62 \mathrm{~V}$ vs RHE, catalysts with low Fe content showed a distinct spectral signature. No significant change was present in the oxidation-state sensitive pre-edge region. The main edge also did not shift, but the structure-sensitive 
oscillations in the post-edge region all shifted to higher energies. This behavior indicates the formation of a structure in which the oxidation state and octahedral coordination of $\mathrm{Fe}^{3+}$ were retained but the $\mathrm{Fe}-\mathrm{O}$ bond distance contracted substantially. A straightforward analysis would indicate that octahedrally coordinated $\mathrm{Fe}$ cations with such a short $\mathrm{Fe}-\mathrm{O}$ distance $(0.189 \mathrm{~nm})$ would be expected to be in the +4 oxidation state. A careful inspection of the pre-edge feature reveals subtle changes that could be interpreted with a small percentage of $\mathrm{Fe}^{4+}$, but the magnitude of this signal is not sufficient to explain the observed average bond length for all $\mathrm{Fe}$ sites, especially in the absence of a pronounced shift in the position of the main-edge signal. The $\sim 1 \mathrm{eV}$ shift of the first absorption maximum can be fully explained in the framework of multiplescattering as an effect of bond contraction. These findings support the hypothesis that the Fe cations remain in the +3 oxidation state, and that the unusually short $\mathrm{Fe}-\mathrm{O}$ bond length is imposed by the role of Fe as a dopant in the $\gamma-\mathrm{NiOOH}$ host structure.

As the Fe content was increased, the differences between spectra obtained at $1.62 \mathrm{~V}$ and $1.12 \mathrm{~V}$ vs RHE, respectively, became less pronounced, consistent with an increasing fraction of strain-free $\mathrm{FeOOH}$ that reaches $100 \%$ for the Ni-free sample. These data are consistent with expectations for formation of a separate, pure $\mathrm{FeOOH}$ phase due to the limited solubility of $\mathrm{Fe}$ in the $\mathrm{NiO}_{x} \mathrm{H}_{y}$ host structure.

In summary, Ni-K and Fe-K edge spectra indicate that at an electrode potential of $1.12 \mathrm{~V}$ vs RHE, the $\mathrm{Ni}$ was present as $\mathrm{Ni}^{2+}$ cations in a coordination environment similar to that of $\alpha$ $\mathrm{Ni}(\mathrm{OH})_{2}$ while $\mathrm{Fe}$ cations are $\mathrm{Fe}^{3+}$ in the coordination environment of $\mathrm{FeOOH} / \mathrm{Fe}^{3+}: \mathrm{LDH}$ distinct from that of pure $\gamma-\mathrm{FeOOH}$. At $1.62 \mathrm{~V}$ and higher potentials, at least $90 \%$ of the Ni cations have been oxidized to $\mathrm{Ni}^{3+/ 4+}$, whereas $\mathrm{Fe}$ shows a $\mathrm{Fe} / \mathrm{Ni}$ composition-dependent trend. At low (0$25 \%) \mathrm{Fe}$ content the $\mathrm{Fe}^{3+}$ species are preset as dopants in $\alpha-\mathrm{Ni}(\mathrm{OH})_{2} / \gamma-\mathrm{NiOOH}$ but at higher $\mathrm{Fe}$ concentrations a separate $\gamma-\mathrm{FeOOH}$ phase forms.

Theoretical calculations using $\mathrm{DFT}+\mathrm{U}$ were performed to further understand the electronic structure of $(\mathrm{Fe}, \mathrm{Ni}) \mathrm{OOH}$ and the influence of $\mathrm{Fe}$ dopants in $\gamma$-NiOOH on OER activity. The results further support the interpretation of the Fe K-edge HERFD XAS that Fe in $\gamma-\mathrm{NiOOH}$ is present as $\mathrm{Fe}^{3+}$ with unusually short $\mathrm{Fe}-\mathrm{O}$ bonds.

Löwdin charges were extracted from DFT $+\mathrm{U}$ calculations. The $\mathrm{O}$ atoms exhibited intermediate charges between the pure $\mathrm{FeOOH}$ and $\gamma-\mathrm{NiOOH}$ end members. Accordingly, an Fe dopant in $\gamma-\mathrm{NiOOH}$ is coordinated with $\mathrm{O}$ ligands that have significantly less-negative charge 
than in pure $\mathrm{FeOOH}$. These results suggest that smaller negative charge reduces the electrostatic repulsion between neighboring $\mathrm{O} / \mathrm{OH}$ anions, and therefore allows for a bond contraction that would not be possible in pure $\mathrm{FeOOH}$ (Fig. 9). Some destabilization of $\gamma-\mathrm{NiOOH}$ with respect to $\alpha-\mathrm{Ni}(\mathrm{OH})_{2}$ due to $\mathrm{Fe}$ doping is apparent in the cyclic voltammetry, in which the $\alpha-\mathrm{Ni}(\mathrm{OH})_{2} / \gamma-$ $\mathrm{NiOOH}$ redox potential shifted positively as the Fe content was increased, consistent with expectations the effects of local strain at the Fe dopant site.

The theoretical calculations, in following the well-established method of predicting activity trends from the free energies of chemisorbed reaction intermediates [39-49], further revealed that $\mathrm{Fe}$ doping changes the affinity to $\mathrm{OH}(\mathrm{ads}), \mathrm{O}(\mathrm{ads})$ and $\mathrm{OOH}(\mathrm{ads})$ intermediates both at $\mathrm{Ni}$ sites (compared to pure $\mathrm{NiOOH}$ ) as well as at Fe sites (compared to pure FeOOH). This effect can be rationalized with the different degree of covalency of the $\mathrm{Fe}-\mathrm{O}$ and $\mathrm{Ni}-\mathrm{O}$ bonding. DFT $+\mathrm{U}$ modeling indicated that the surface metal atom that provides the catalytically active site changes its oxidation state during each elementary step of the OER, with local oxidation state increases during the formation of $\mathrm{OH}(\mathrm{ads})$ and $\mathrm{O}$ (ads) intermediates, and oxidation state decreases during formation of $\mathrm{OOH}(\mathrm{ads})$ and $\mathrm{O}_{2}(\mathrm{~g})$. Such intermediate-induced oxidation state changes have been previously discussed for hematite photoanodes, with electrooxidation inducing high-valent Fe surface species [50-52]. Comparing an Fe site at a pure $\mathrm{FeOOH}$ surface with an Fe surface site at a $\gamma-\mathrm{NiOOH}$ surface, the electron-withdrawing effect of $\mathrm{Ni}$ sites makes the oxidative steps of $\mathrm{OH}(\mathrm{ads})$ and $\mathrm{O}(\mathrm{ads})$ formation at the Fe site less favorable energetically, while reducing the free energy needed to further convert $\mathrm{O}(\mathrm{ads})$ to $\mathrm{OOH}(\mathrm{ads})$. Likewise, formation of $\mathrm{O}(\mathrm{ads})$ from $\mathrm{OH}(\mathrm{ads})$ becomes more endergonic at a Ni site in $\gamma-\mathrm{NiOOH}$, if $\mathrm{Ni}$ atoms are substituted for $\mathrm{Fe}$ atoms in the neighborhood of the active $\mathrm{Ni}$ site. This theoretical model of the $\mathrm{Ni}-\mathrm{O}$ interaction at $\mathrm{Ni}$ surface sites is consistent with the experimentally observed positive shift of the redox potential at bulk Ni sites upon addition of Fe [24].

An optimal OER catalyst requires equal free energies for the conversion from $\mathrm{OH}(\mathrm{ads})$ to $\mathrm{O}(\mathrm{ads})$ as well as for the conversion from $\mathrm{O}(\mathrm{ads})$ to $\mathrm{OOH}(\mathrm{ads})$ [47]. Most surface sites of pure $\gamma-\mathrm{NiOOH}$ tend towards formation of $\mathrm{O}(\mathrm{ads})$ being the overpotential-determining step, while $\mathrm{OOH}(\mathrm{ads})$ formation is overpotential-determining at the more oxophilic surfaces of $\mathrm{FeOOH}$. Therefore, the effect of combining Fe and Ni into a mixed oxyhydroxide is that the site-specific OER activity at Ni surface atoms further decreases compared to pure $\gamma-\mathrm{NiOOH}$, whereas the activity at Fe surface sites increases compared to pure $\mathrm{FeOOH}$, because the energetics of OER 
intermediates shift towards optimal binding energies. At Fe surface atoms in ( $\mathrm{Fe}, \mathrm{Ni}) \mathrm{OOH}$, nearoptimal adsorption energies of intermediates could be achieved; therefore, the active site in $(\mathrm{Fe}, \mathrm{Ni}) \mathrm{OOH}$ is the $\mathrm{Fe}$ dopant. This finding is in good agreement with previous computational work on Ni-doped hematite [44] and with a recent combined theoretical and experimental study of double hydroxides [39]. In comparing our results with these two studies, it is noteworthy that the most important contribution to the enhancement of the OER activity at Fe sites is the electronic effect arising from the proximity of $\mathrm{FeO}_{6}$ and $\mathrm{NiO}_{6}$ octahedra, which seems to be qualitatively independent of the specific coordination geometry. Theoretical modelling and experiments by Diaz-Morales et al.[39], and results from a variant of scanning electrochemical microscopy designed by Ahn and Bard[53], furthermore support the assignment of $\mathrm{Fe}$ as the active site. Furthermore, it has been proposed that even the poor OER activity of pure FeOOH does not match with a revised general trend for transition metal oxyhydroxides [54], and that a high intrinsic activity of Fe sites could be masked by the lack of electronic conductivity in $\mathrm{FeOOH}[41]$.

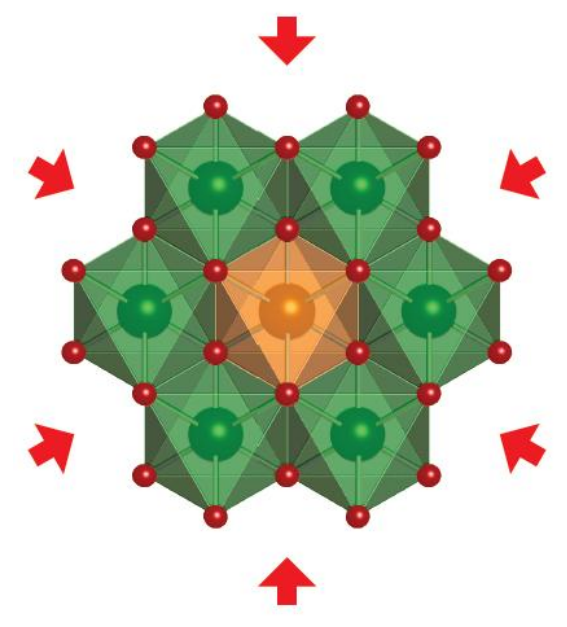

Figure 9: Interpretation of the XAS results with regard to the bond lengths in mixed Ni-Fe oxide compounds; arrows indicate compression of the $\mathrm{Fe}-\mathrm{O}$ bond length to that of $\gamma \mathrm{NiOOH}$ (see text).

\section{Conclusions}

Operando techniques enable the investigation of functioning semiconductor/liquid and catalytic systems. Operando APXPS has been used to investigate the nature of depletion, Fermi level pinning, and other parameters in semiconductor/liquid systems. In addition, HERFD + EXAFS analysis of catalysts for the oxygen-evolution reaction has revealed the changes in the 
electronic and physical structure of the metal sites in the catalysts. Further work is ongoing to expand the capabilities of such techniques to other molecules and materials of interest in solar fuels production.

\section{Acknowledgements}

This work was supported by the Office of Science of the U.S. Department of Energy (DOE) through award no. DE-SC0004993 to the Joint Center for Artificial Photosynthesis. The Advanced Light Source acknowledges support by the Director, Office of Science, Office of Basic Energy Sciences, of the U.S. Department of Energy under Contract no. DE-AC0205CH11231. XAS data collection was carried out at Stanford Synchrotron Radiation Lightsource, a National User Facility operated by Stanford University on behalf of the U.S. Department of Energy, Office of Basic Energy Sciences. Computational work was carried out through NERSC computational resources under DOE Contract No. DE-AC02-05CH11231. 


\section{References}

[1] M.G. Walter, E.L. Warren, J.R. McKone, S.W. Boettcher, Q. Mi, E.A. Santori, N.S. Lewis, Solar Water Splitting Cells, Chem. Rev., 110 (2010) 6446-6473.

[2] N.S. Lewis, An Integrated, Systems Approach to the Development of Solar Fuel Generators, The Electrochemical Society's Interface, 22 (2013) 43-50.

[3] N.S. Lewis, D.G. Nocera, Powering the planet: Chemical challenges in solar energy utilization, P. N. A. S., 103 (2006) 15729-15735.

[4] F.F. Abdi, T.J. Savenije, M.M. May, B. Dam, R. van de Krol, The Origin of Slow Carrier Transport in BiVO4 Thin Film Photoanodes: A Time-Resolved Microwave Conductivity Study, J. Phys. Chem. Lett., 4 (2013) 2752-2757.

[5] F.F. Abdi, L. Han, A.H.M. Smets, M. Zeman, B. Dam, R. van de Krol, Efficient solar water splitting by enhanced charge separation in a bismuth vanadate-silicon tandem photoelectrode, Nat. Commun., 4 (2013).

[6] M.F. Lichterman, M.R. Shaner, S.G. Handler, B.S. Brunschwig, H.B. Gray, N.S. Lewis, J.M. Spurgeon, Enhanced Stability and Activity for Water Oxidation in Alkaline Media with Bismuth Vanadate Photoelectrodes Modified with a Cobalt Oxide Catalytic Layer Produced by Atomic Layer Deposition, J. Phys. Chem. Lett., 4 (2013) 4188-4191.

[7] S. Hu, C. Xiang, S. Haussener, A.D. Berger, N.S. Lewis, An analysis of the optimal band gaps of light absorbers in integrated tandem photoelectrochemical water-splitting systems, Energy Environ. Sci., 6 (2013) 2984-2993.

[8] S. Haussener, C. Xiang, J.M. Spurgeon, S. Ardo, N.S. Lewis, A.Z. Weber, Modeling, simulation, and design criteria for photoelectrochemical water-splitting systems, Energy Environ. Sci., 5 (2012) 99229935.

[9] J. Gobrecht, H. Gerischer, H. Tributsch, Electrochemical Solar Cell Based on the d-Band Semiconductor Tungsten-Diselenide, Berichte der Bunsengesellschaft für physikalische Chemie, 82 (1978) 1331-1335.

[10] H.J. Lewerenz, A. Heller, F.J. DiSalvo, Relationship between surface morphology and solar conversion efficiency of tungsten diselenide photoanodes, J. Am. Chem. Soc., 102 (1980) 1877-1880.

[11] S. Hu, M.R. Shaner, J.A. Beardslee, M.F. Lichterman, B.S. Brunschwig, N.S. Lewis, Amorphous TiO2 coatings stabilize Si, GaAs, and GaP photoanodes for efficient water oxidation, Science, 344 (2014) 10051009.

[12] K. Sun, N. Park, Z. Sun, J. Zhou, J. Wang, X. Pang, S. Shen, S.Y. Noh, Y. Jing, S. Jin, P.K.L. Yu, D. Wang, Nickel oxide functionalized silicon for efficient photo-oxidation of water, Energy Environ. Sci., 5 (2012) 7872-7877.

[13] K. Sun, F.H. Saadi, M.F. Lichterman, W.G. Hale, H.-P. Wang, X. Zhou, N.T. Plymale, S.T. Omelchenko, J.-H. He, K.M. Papadantonakis, B.S. Brunschwig, N.S. Lewis, Stable solar-driven oxidation of water by semiconducting photoanodes protected by transparent catalytic nickel oxide films, P. N. A. S., 112 (2015) 3612-3617.

[14] Y.W. Chen, J.D. Prange, S. Dühnen, Y. Park, M. Gunji, C.E.D. Chidsey, P.C. McIntyre, Atomic layerdeposited tunnel oxide stabilizes silicon photoanodes for water oxidation, Nat Mater, 10 (2011) 539544.

[15] B. Seger, D.S. Tilley, T. Pedersen, P.C.K. Vesborg, O. Hansen, M. Gratzel, I. Chorkendorff, Silicon protected with atomic layer deposited TiO2: durability studies of photocathodic $\mathrm{H} 2$ evolution, RSC Adv., 3 (2013) 25902-25907.

[16] A. Heller, B. Miller, H.J. Lewerenz, K.J. Bachmann, An efficient photocathode for semiconductor liquid junction cells: 9.4\% solar conversion efficiency with $\mathrm{p}-\mathrm{InP} / \mathrm{VCl} 3-\mathrm{VCl} 2-\mathrm{HCl} / \mathrm{C}$, J. Am. Chem. Soc., 102 (1980) 6555-6556. 
[17] K.H. Schulte, H.J. Lewerenz, Combined photoelectrochemical conditioning and photoelectron spectroscopy analysis of InP photocathodes. I. The modification procedure, Electrochimica Acta, 47 (2002) 2633-2638.

[18] M.F. Lichterman, S. Hu, M.H. Richter, E.J. Crumlin, S. Axnanda, M. Favaro, W. Drisdell, Z. Hussain, T. Mayer, B.S. Brunschwig, N.S. Lewis, Z. Liu, H.-J. Lewerenz, Direct observation of the energetics at a semiconductor/liquid junction by operando X-ray photoelectron spectroscopy, Energy Environ. Sci., 8 (2015) 2409-2416.

[19] M.F. Lichterman, M.H. Richter, S. Hu, E.J. Crumlin, S. Axnanda, M. Favaro, W. Drisdell, Z. Hussain, B.S. Brunschwig, N.S. Lewis, Z. Liu, H.-J. Lewerenz, An Electrochemical, Microtopographical and Ambient Pressure X-Ray Photoelectron Spectroscopic Investigation of $\mathrm{Si} / \mathrm{TiO} 2 / \mathrm{Ni} /$ Electrolyte Interfaces, J. Electrochem. Soc., 163 (2016) H139-H146.

[20] E.J. Crumlin, Z. Liu, H. Bluhm, W. Yang, J. Guo, Z. Hussain, X-ray spectroscopy of energy materials under in situ/operando conditions, Journal of Electron Spectroscopy and Related Phenomena, 200 (2015) 264-273.

[21] H.G. Manyar, R. Morgan, K. Morgan, B. Yang, P. Hu, J. Szlachetko, J. S, C. Hardacre, High energy resolution fluorescence detection XANES ? an in situ method to study the interaction of adsorbed molecules with metal catalysts in the liquid phase, Catalysis Science \& Technology, 3 (2013) 1497-1500.

[22] D. Friebel, M.W. Louie, M. Bajdich, K.E. Sanwald, Y. Cai, A.M. Wise, M.-J. Cheng, D. Sokaras, T.-C. Weng, R. Alonso-Mori, R.C. Davis, J.R. Bargar, J.K. Nørskov, A. Nilsson, A.T. Bell, Identification of Highly Active Fe Sites in (Ni,Fe)OOH for Electrocatalytic Water Splitting, J. Am. Chem. Soc., 137 (2015) 13051313.

[23] M.F. Lichterman, K. Sun, S. Hu, X. Zhou, M.T. McDowell, M.R. Shaner, M.H. Richter, E.J. Crumlin, A.I. Carim, F.H. Saadi, B.S. Brunschwig, N.S. Lewis, Protection of inorganic semiconductors for sustained, efficient photoelectrochemical water oxidation, Catalysis Today.

[24] M.W. Louie, A.T. Bell, An Investigation of Thin-Film Ni-Fe Oxide Catalysts for the Electrochemical Evolution of Oxygen, J. Am. Chem. Soc., 135 (2013) 12329-12337.

[25] S. Tanuma, C.J. Powell, D.R. Penn, Calculations of electron inelastic mean free paths. V. Data for 14 organic compounds over the 50-2000 eV range, Surface and Interface Analysis, 21 (1994) 165-176.

[26] M.B. Trzhaskovskaya, V.I. Nefedov, V.G. Yarzhemsky, Photoelectron Angular Distribution Parameters for Elements $Z=1$ to $Z=54$ in the Photoelectron Energy Range 100 -5000 eV, Atomic Data and Nuclear Data Tables, 77 (2001) 97-159.

[27] S. Axnanda, E.J. Crumlin, B. Mao, S. Rani, R. Chang, P.G. Karlsson, M.O.M. Edwards, M. Lundqvist, R. Moberg, P. Ross, Z. Hussain, Z. Liu, Using "Tender" X-ray Ambient Pressure X-Ray Photoelectron Spectroscopy as A Direct Probe of Solid-Liquid Interface, Scientific Reports, 5 (2015) 9788.

[28] M.H. Richter, M.F. Lichterman, S. Hu, E.J. Crumlin, T. Mayer, S. Axnanda, M. Favaro, W. Drisdell, Z. Hussain, B. Brunschwig, N.S. Lewis, Z. Liu, H.J. Lewerenz, (Invited) Measurement of the Energy-Band Relations of Stabilized Si Photoanodes Using Operando Ambient Pressure X-ray Photoelectron Spectroscopy, ECS Trans., 66 (2015) 105-113.

[29] A.J. Bard, A.B. Bocarsly, F.R.F. Fan, E.G. Walton, M.S. Wrighton, The concept of Fermi level pinning at semiconductor/liquid junctions. Consequences for energy conversion efficiency and selection of useful solution redox couples in solar devices, J. Am. Chem. Soc., 102 (1980) 3671-3677.

[30] S. Tanaka, J.A. Bruce, M.S. Wrighton, Deliberate modification of the behavior of n-type cadmium telluride/electrolyte interfaces by surface etching. Removal of Fermi level pinning, J. Phys. Chem., 85 (1981) 3778-3787.

[31] M. Zhu, Y. Mi, G. Zhu, D. Li, Y. Wang, Y. Weng, Determination of Midgap State Energy Levels of an Anatase TiO2 Nanocrystal Film by Nanosecond Transient Infrared Absorption - Excitation Energy Scanning Spectra, The Journal of Physical Chemistry C, 117 (2013) 18863-18869. 
[32] H. Yaghoubi, Z. Li, Y. Chen, H.T. Ngo, V.R. Bhethanabotla, B. Joseph, S. Ma, R. Schlaf, A. Takshi, Toward a Visible Light-Driven Photocatalyst: The Effect of Midgap-States-Induced Energy Gap of Undoped TiO2 Nanoparticles, ACS Catalysis, 5 (2015) 327-335.

[33] R.C. Rossi, N.S. Lewis, Investigation of the Size-Scaling Behavior of Spatially Nonuniform Barrier Height Contacts to Semiconductor Surfaces Using Ordered Nanometer-Scale Nickel Arrays on Silicon Electrodes, J. Phys. Chem. B, 105 (2001) 12303-12318.

[34] M. Balasubramanian, C.A. Melendres, S. Mini, X-ray Absorption Spectroscopy Studies of the Local Atomic and Electronic Structure of Iron Incorporated into Electrodeposited Hydrous Nickel Oxide Films, J. Phys. Chem. B, 104 (2000) 4300-4306.

[35] D.K. Bediako, B. Lassalle-Kaiser, Y. Surendranath, J. Yano, V.K. Yachandra, D.G. Nocera, StructureActivity Correlations in a Nickel-Borate Oxygen Evolution Catalyst, J. Am. Chem. Soc., 134 (2012) 68016809.

[36] T.W. Capehart, D.A. Corrigan, R.S. Conell, K.I. Pandya, R.W. Hoffman, Insitu extended x-ray absorption fine structure spectroscopy of thin-film nickel hydroxide electrodes, Appl. Phys. Lett., 58 (1991) 865-867.

[37] Y. Hu, I.T. Bae, Y. Mo, D.A. Scherson, M.R. Antonio, In situ X-ray absorption fine structure and optical reflectance studies of electrodeposited nickel hydrous oxide films in alkaline electrolytes, Canadian Journal of Chemistry, 75 (1997) 1721-1729.

[38] A.N. Mansour, C.A. Melendres, XAFS investigation of the structure and valency of nickel in some oxycompounds, Physica B: Condensed Matter, 208-209 (1995) 583-584.

[39] O. Diaz-Morales, I. Ledezma-Yanez, M.T.M. Koper, F. Calle-Vallejo, Guidelines for the Rational Design of Ni-Based Double Hydroxide Electrocatalysts for the Oxygen Evolution Reaction, ACS Catalysis, 5 (2015) 5380-5387.

[40] M. García-Mota, M. Bajdich, V. Viswanathan, A. Vojvodic, A.T. Bell, J.K. Nørskov, Importance of Correlation in Determining Electrocatalytic Oxygen Evolution Activity on Cobalt Oxides, J. Phys. Chem. C, 116 (2012) 21077-21082.

[41] S. Klaus, L. Trotochaud, M.-J. Cheng, M. Head-Gordon, A.T. Bell, Experimental and Computational Evidence of Highly Active Fe Impurity Sites on the Surface of Oxidized Au for the Electrocatalytic Oxidation of Water in Basic Media, ChemElectroChem, 3 (2016) 173-173.

[42] M.T.M. Koper, Thermodynamic theory of multi-electron transfer reactions: Implications for electrocatalysis, Journal of Electroanalytical Chemistry, 660 (2011) 254-260.

[43] Y.-F. Li, A. Selloni, Mechanism and Activity of Water Oxidation on Selected Surfaces of Pure and FeDoped NiOx, ACS Catalysis, 4 (2014) 1148-1153.

[44] P. Liao, J.A. Keith, E.A. Carter, Water Oxidation on Pure and Doped Hematite (0001) Surfaces: Prediction of Co and Ni as Effective Dopants for Electrocatalysis, J. Am. Chem. Soc., 134 (2012) 1329613309.

[45] I.C. Man, H.-Y. Su, F. Calle-Vallejo, H.A. Hansen, J.I. Martínez, N.G. Inoglu, J. Kitchin, T.F. Jaramillo, J.K. Nørskov, J. Rossmeisl, Universality in Oxygen Evolution Electrocatalysis on Oxide Surfaces, ChemCatChem, 3 (2011) 1159-1165.

[46] J.K. Nørskov, J. Rossmeisl, A. Logadottir, L. Lindqvist, J.R. Kitchin, T. Bligaard, H. Jónsson, Origin of the Overpotential for Oxygen Reduction at a Fuel-Cell Cathode, J. Phys. Chem. B, 108 (2004) 1788617892.

[47] J. Rossmeisl, Z.W. Qu, H. Zhu, G.J. Kroes, J.K. Nørskov, Electrolysis of water on oxide surfaces, Journal of Electroanalytical Chemistry, 607 (2007) 83-89.

[48] S.-M. Xu, T. Pan, Y.-B. Dou, H. Yan, S.-T. Zhang, F.-Y. Ning, W.-Y. Shi, M. Wei, Theoretical and Experimental Study on MIIMIII-Layered Double Hydroxides as Efficient Photocatalysts toward Oxygen Evolution from Water, J. Phys. Chem. C, 119 (2015) 18823-18834. 
[49] M. Bajdich, M. García-Mota, A. Vojvodic, J.K. Nørskov, A.T. Bell, Theoretical Investigation of the Activity of Cobalt Oxides for the Electrochemical Oxidation of Water, J. Am. Chem. Soc., 135 (2013) 13521-13530.

[50] D.K. Bora, A. Braun, S. Erat, A.K. Ariffin, R. Löhnert, K. Sivula, J. Töpfer, M. Grätzel, R. Manzke, T. Graule, E.C. Constable, Evolution of an Oxygen Near-Edge X-ray Absorption Fine Structure Transition in the Upper Hubbard Band in $\alpha-F e 2 O 3$ upon Electrochemical Oxidation, J. Phys. Chem. C, 115 (2011) 56195625.

[51] A. Braun, Y. Hu, F. Boudoire, D.K. Bora, D.D. Sarma, M. Grätzel, C.M. Eggleston, The electronic, chemical and electrocatalytic processes and intermediates on iron oxide surfaces during photoelectrochemical water splitting, Catalysis Today, 260 (2016) 72-81.

[52] C.Y. Cummings, F. Marken, L.M. Peter, K.G. Upul Wijayantha, A.A. Tahir, New Insights into Water Splitting at Mesoporous $\alpha$-Fe2O3 Films: A Study by Modulated Transmittance and Impedance Spectroscopies, J. Am. Chem. Soc., 134 (2012) 1228-1234.

[53] H.S. Ahn, A.J. Bard, Surface Interrogation Scanning Electrochemical Microscopy of Ni1-xFexOOH (0 $<x<0.27)$ Oxygen Evolving Catalyst: Kinetics of the "fast" Iron Sites, J. Am. Chem. Soc., 138 (2016) 313318.

[54] M.S. Burke, S. Zou, L.J. Enman, J.E. Kellon, C.A. Gabor, E. Pledger, S.W. Boettcher, Revised Oxygen Evolution Reaction Activity Trends for First-Row Transition-Metal (Oxy)hydroxides in Alkaline Media, J. Phys. Chem. Lett., 6 (2015) 3737-3742. 